\title{
Posttraumatic stress in school-age children and adolescents: medical providers' role from diagnosis to optimal management
}

This article was published in the following Dove Press journal:

Pediatric Health, Medicine and Therapeutics

3 October 2015

Number of times this article has been viewed

\author{
Katharine Donlon Ramsdell' \\ Andrew J Smith' \\ Aimee $\mathrm{K}$ Hildenbrand ${ }^{2}$ \\ Meghan L Marsac ${ }^{3}$ \\ 'Department of Psychology, Virginia \\ Tech, Blacksburg, VA, ${ }^{2}$ Department \\ of Psychology, Drexel University, \\ Philadelphia, PA, ${ }^{3}$ University of \\ Pennsylvania and The Children's \\ Hospital of Philadelphia, Philadelphia, \\ PA, USA
}

\begin{abstract}
Millions of children and adolescents each year are exposed to potentially traumatic events (PTEs), placing them at risk for posttraumatic stress (PTS) disorder symptoms. Medical providers play an important role in the identification and treatment of PTS, as they are typically the initial point of contact for families in the wake of a PTE or during a PTE if it is medically related (eg, injury/illness). This paper offers a review of the literature focused on clinical characteristics of PTS, the assessment and diagnosis of PTS, and current effective treatments for PTS in school-age children and adolescents. The clinical presentation of PTS is often complex as symptoms may closely resemble other internalizing and externalizing disorders. A number of screening and evaluation tools are available for medical providers to assist them in the accurate diagnosis of PTS. Treatment options are available for youth at minimal risk of PTS as well as for those with more intensive needs. Additional training regarding trauma-informed medical care may benefit medical providers. By taking a trauma-informed approach, rooted in a solid understanding of the clinical presentation of PTS in children and adolescents, medical providers can ensure PTS does not go undetected, minimize the traumatic aspects of medical care, and better promote health and well-being.
\end{abstract}

Keywords: posttraumatic stress, medical traumatic stress, children, primary care, assessment, treatment

\section{Introduction}

Childhood trauma exposure is unfortunately prevalent. According to a national survey in the USA, $60 \%$ of children and adolescents have experienced or witnessed a potentially traumatic event (PTE), ${ }^{1}$ such as domestic violence, injuries, and natural disasters. ${ }^{2-4}$ Approximately $30 \%$ of youth who are exposed to a PTE develop symptoms of posttraumatic stress disorder (PTSD), ${ }^{5}$ and an additional subset experience significant, chronic symptoms of posttraumatic stress (PTS). For instance, while PTS resolves for a majority of children and adolescents within 3 months of a potentially traumatic injury, approximately $15 \%-25 \%$ will experience chronic symptoms. ${ }^{6-9}$ Chronic PTS can adversely affect child health and development and lead to worse functional outcomes. ${ }^{10-14}$

Empirical evidence indicates that PTS is more likely to go unnoticed and untreated in children and adolescents than adults; this may result from the challenging nature of the expression of PTS in youth (eg, internalizing symptoms that children do not share with adults; adults mistaking externalizing symptoms for oppositional behaviors). ${ }^{15-18}$ However, early identification of youth at risk for PTS can help reduce morbidity, societal cost, and long-term disability through the implementation of early interventions. ${ }^{19-23}$ 
Following exposure to a PTE, many children and families interact with medical providers. Most will report to their primary care provider first for assistance dealing with a PTE. ${ }^{24}$ As medical providers are typically the first line of defense in the wake of traumatic experiences, it is important that they are well equipped to manage PTS, yet most receive little training. ${ }^{25,26}$ Although PTS cannot be diagnosed until symptoms have persisted for at least 1 month, significant symptoms may emerge shortly after the PTE, providing an opportunity for providers to support and monitor these children and adolescents. Developed specifically for medical providers practicing within the USA, the American Academy of Child and Adolescent Psychiatry (AACAP) created guidelines for the management of youth with PTS. Regarding assessment guidelines, the AACAP recommends that medical providers routinely ask questions about PTEs and possible PTS, conduct a formal evaluation if symptoms are endorsed, and pay particular attention to possible differential diagnoses. Furthermore, the AACAP guidelines indicate the treatment approach should be developed based on consideration of the severity and degree of impairment of the symptoms and should incorporate appropriate interventions for comorbid disorders. Psychotherapy is recommended as the first-line treatment, although the AACAP practice parameters also specify that selective serotonin reuptake inhibitors (SSRIs) as well as medications other than SSRIs may be used for treatment. The use of therapies involving binding or restriction (eg, rebirthing therapies) is not supported. ${ }^{27}$

Thus, in line with the aforementioned AACAP guidelines, the purpose of this review is to provide information to strengthen medical providers' knowledge about assessment and treatment for PTS following trauma exposure in school-age children and adolescents. The information presented in this paper is focused for US-based practitioners; however, much of the information is relevant to those in other developed countries as long as cultural differences are considered. For providers practicing in countries with fewer resources, youth responses to treatment and guidelines post-PTE may differ from research and recommendations presented here. The following narrative review includes the clinical characteristics of PTS, assessment and diagnosis of PTS, and current effective treatments for PTS in school-age children and adolescents (Figure 1 provides a summary of specific steps for medical providers).

\section{Clinical presentation of childhood PTSD}

Recognizing PTSD symptom presentation in primary care or other medical settings can promote recovery and healthy development in children and adolescents exposed to PTEs. The Diagnostic and Statistical Manual of Mental Disorders, Fifth Edition (DSM-5) differentiates PTS symptoms across four distinct symptom clusters, providing an initial roadmap for identifying those who may be struggling with such symptoms. DSM-5 accounts for developmental considerations with modified criteria for youth older than 6 years. Table 1 lists criteria and examples of how symptoms may present in school-age children and adolescents. Regardless of whether their symptoms meet full diagnostic criteria, high levels of distress and functional impairment can occur amidst symptoms that do not meet diagnostic threshold of PTSD. ${ }^{28-30}$ Children and adolescents who are struggling from significant PTSD symptoms but who do not qualify for a diagnosis for PTSD may benefit from consideration of PTS from a dimensional perspective (ie, severity of symptoms and subsequent impairment); this offers flexibility in recognizing symptoms that require clinical attention apart from diagnostic status. ${ }^{31}$

\section{Co-occurring symptoms and comorbidities: initial recognition of PTS}

In children and adolescents, PTEs and subsequent PTS may manifest in the form of internalizing and externalizing symptoms that do not fit neatly within the PTSD diagnostic criteria. Such symptoms may well originate from and represent underlying PTS. For example, symptoms may devolve into anxiety about separating from one's caregiver, ${ }^{32}$ shame, and/or guilt. ${ }^{33}$ Alternatively, or in addition, youth may present with low frustration tolerance or seem as though a breaking point is imminent at any moment. ${ }^{34}$ Thus, it is not surprising that significant rates of comorbidities are evident between PTS and the following disorders: 1) attentiondeficit hyperactivity disorder (ADHD), ${ }^{35}$ as hyperarousal can present as hyperactivity and impulsivity and intrusive thoughts can impair attention and concentration; ${ }^{36,37} 2$ ) externalizing disorders such as conduct disorder (CD) or oppositional defiant disorder (ODD), as youth with PTS may exhibit temper outbursts, defiance, hostility, and aggression due to underlying symptoms of irritability, extreme avoidance, and hypersensitivity; ${ }^{36} 3$ ) obsessive compulsive disorder (OCD), a disorder characterized by recurrent, intrusive thoughts, similar to the reexperiencing symptoms of PTS; ${ }^{36} 4$ ) anxiety disorders, as the avoidance, irritability, arousal, and anxiety associated with panic disorder and generalized anxiety disorder are also characteristic of PTS; ${ }^{36}$ and 5) traumatic brain injury (TBI), as youth who 


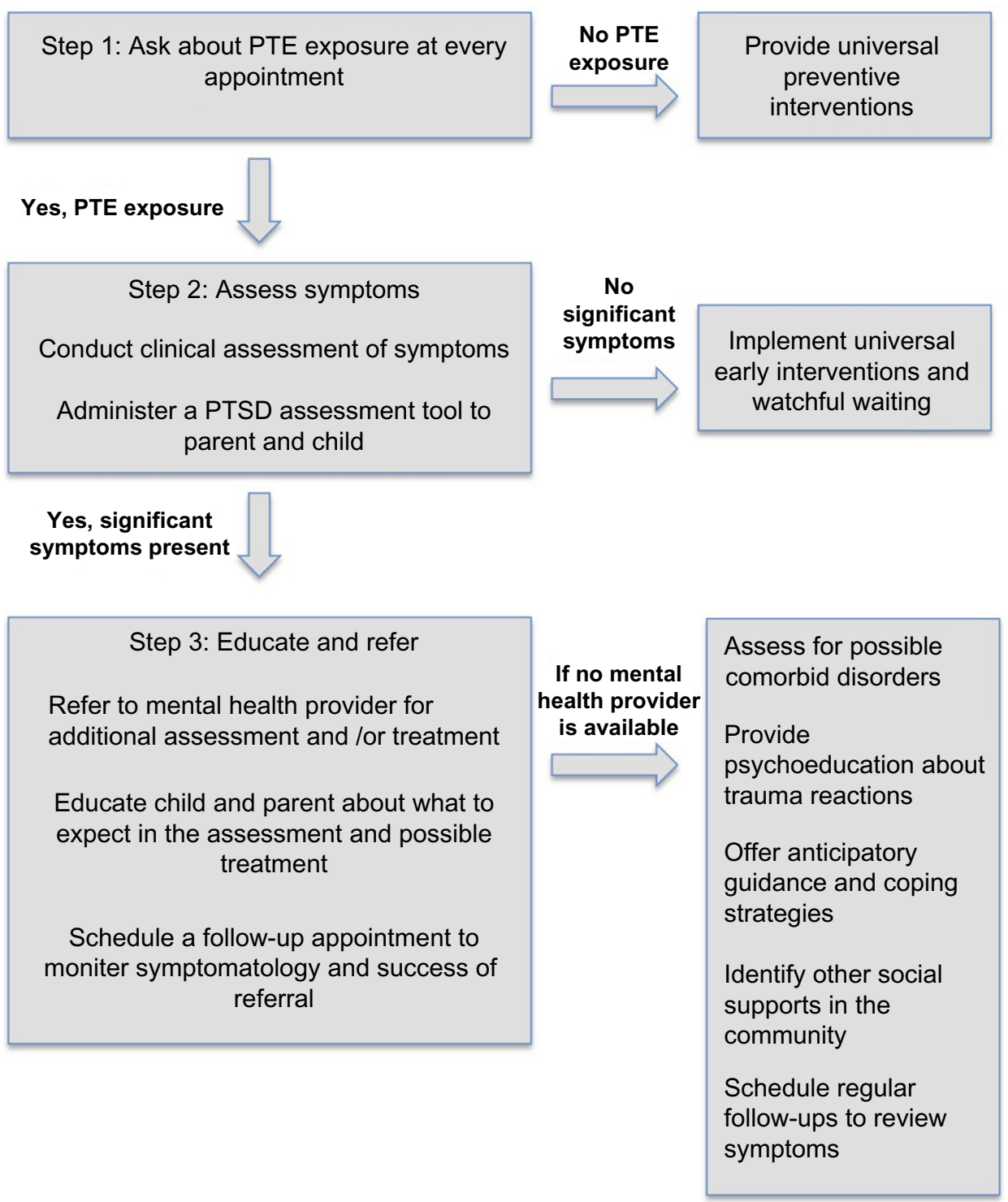

Figure I Steps for medical providers for assessing, diagnosing, and supporting management of PTSD symptoms. Abbreviations: PTE, potentially traumatic event; PTSD, posttraumatic stress disorder.

have incurred a TBI may report somatic, mood, and cognitive changes that overlap with some symptoms of PTS (eg, irritability, concentration difficulties). ${ }^{36}$ While there may be some overlap between PTS and other disorders, providers ought to take caution in making these diagnoses to determine whether PTS are causing or contributing to the observed behaviors.

\section{Consideration for complex trauma: consistently inconsistent clinical presentation}

Among children and adolescents who are chronically exposed to PTEs and/or maltreatment, symptoms may be more diffuse and difficult to categorize. The effects of chronic trauma can cause changes in neurobiological development as well as the ability to integrate sensory, emotional, and cognitive information; children rarely demonstrate a discrete change in behavior, as occurs following an acute PTE. ${ }^{38}$ Complex trauma is defined as severe stressors that 1) are repetitive or prolonged, 2) involve harm or abandonment by caregivers or other ostensibly responsible adults, and 3) occur at developmentally vulnerable times in the victim's life, such as early childhood or adolescence. ${ }^{39}$

While complex trauma disorders are beyond the scope of this paper, it is important to note that children and adolescents who are suspected of having experienced chronic trauma exposure and/or maltreatment greatly benefit from expert assessment and treatment, and generally should be 
Table I PTS and examples of manifestation in school-age children and adolescents

\begin{tabular}{|c|c|c|}
\hline PTS symptom cluster & Symptom & Example \\
\hline \multirow[t]{10}{*}{ Intrusion symptoms } & Involuntary, distressing memories & Child who is sexually assaulted perseverates on hypersexualized content \\
\hline & of the traumatic event & when drawing or painting at school. \\
\hline & Recurrent, distressing dreams & Child who witnesses a homicide wakes up screaming multiple times per night \\
\hline & & in nightmares, with or without the ability to recall the content of the dreams. \\
\hline & Flashbacks & Child exposed to physical abuse from a caregiver re-enacting the events in \\
\hline & & play with other children. \\
\hline & Distress when exposed to external & Child injured in a car accident shows fearful apprehension, such as a panic \\
\hline & or internal trauma reminders & attack, while riding in a car. \\
\hline & Physiological reactions when exposed to & Child who survived a hurricane experiences increased heart rate, agitation, and \\
\hline & external or internal trauma reminders & sweating when learning of thunderstorm warnings in the weather forecast. \\
\hline \multirow[t]{3}{*}{ Avoidance symptoms } & Avoidance of memories, thoughts, or & Adolescent increases intake of marijuana to escape trauma-related thoughts and \\
\hline & feelings associated with the trauma & feelings (eg, guilt associated with car accident where adolescent was the driver). \\
\hline & Attempts to avoid external reminders & Child retreats to his bedroom to play video games when his parents begin to \\
\hline \multirow{15}{*}{$\begin{array}{l}\text { Alterations in mood } \\
\text { and cognition }\end{array}$} & Difficulty remembering important & Desnite having no sions or symotoms of concussion child who survives a car \\
\hline & aspects of the trauma & accident is unable to recall details of the rescue. \\
\hline & Exaggerated negative beliefs or & Adolescent who witnesses his father physically abusing his mother begins to \\
\hline & $\begin{array}{l}\text { expectations about oneself, others, } \\
\text { or the world }\end{array}$ & carry a weapon to school to compensate for living in a dangerous world. \\
\hline & Guilt and/or blaming self/others & Child expresses her feelings of guilt associated with the car accident that her \\
\hline & regarding the trauma or its & family was in because the accident occurred after her father had picked her \\
\hline & consequences & up from soccer practice. \\
\hline & Negative emotions (eg, fear, horror, & Child develops low frustration tolerance and frequent temper outbursts after \\
\hline & anger, guilt, or shame) & witnessing his best friend sustain injuries after falling out of a tree house. \\
\hline & Lack of interest in participating in & Adolescent previously took great joy in being involved in school theater decides \\
\hline & previously preferred activities & not to participate in the school play after the family home was lost in a fire. \\
\hline & Feelings of detachment from others & Adolescent who was previously engaged in close friendships begins to isolate \\
\hline & & himself after finding his grandparent deceased. \\
\hline & Inability to experience positive & Child has more difficulty expressing strong loving feelings toward parents \\
\hline & emotions & after being attacked by a neighbor's dog. \\
\hline \multirow{8}{*}{$\begin{array}{l}\text { Alterations in arousal } \\
\text { and reactivity }\end{array}$} & Irritable behavior, angry outbursts, & Adolescent demonstrates increased oppositional behavior toward teachers \\
\hline & and/or aggression & after witnessing community violence. \\
\hline & Reckless or self-destructive behavior & Adolescent engages in risky driving behaviors after being diagnosed with cancer. \\
\hline & Hypervigilance & Child who lived through a tornado becomes fixated on changes in the weather. \\
\hline & Exaggerated startle response & Adolescent whose best friend was shot while the two of them were walking \\
\hline & & home from school is jumpy whenever he hears loud noises in public places. \\
\hline & Problems with concentration & $\begin{array}{l}\text { Child's grades and ability to maintain attention in class begins to slip after } \\
\text { following an illness diagnosis of a parent. }\end{array}$ \\
\hline & Sleep disturbance & Child unable to sleep in own bed following a bullying incident at school. \\
\hline
\end{tabular}

Abbreviation: PTS, posttraumatic stress.

referred for a psychological evaluation if they are reporting symptoms. ${ }^{40}$

\section{Assessment of PTS in school-age children and adolescents Initial assessment process}

Medical providers play an important role in the initial screening process for PTS given that they are more likely to come into contact with children and adolescents following PTEs than mental health professionals. ${ }^{41}$ They can effectively screen for symptoms by inquiring about coping mechanisms and youths' appraisals of the event to better understand who may be at risk for PTS..$^{42}$ As parental report may be influenced by parents' own symptomatology, it is also critical to obtain children's and adolescents' self-reports in addition to parents' perspectives whenever possible. ${ }^{43}$ In addition to eliciting symptoms directly from youths and parents during clinical examinations, a number of screening measures for PTS have been developed by medical professionals. Such instruments are typically brief and easy to administer, making them a viable option for use in an acute care or primary care setting. The Screening Tool for Early Predictors of PTSD (STEPP), the UCLA Posttraumatic Stress Disorder - Reaction Index (UCLA-PTSD-RI), and the Trauma Symptom Checklist for Children (TSCC) are evidence-based screening instruments. The STEPP is a tool developed for use in the emergency 
department following pediatric injury and is based on early physiological reactions (eg, heart rate) and early psychological responses to the trauma. ${ }^{7}$ The UCLA-PTSD-RI is a brief measure assessing exposure to traumatic exposure and the impact of those experiences, ${ }^{44}$ and the TSCC is self-report measure designed to elicit information regarding traumarelated symptoms. ${ }^{45,46}$

Evaluating children and adolescents for PTS in an acute care or primary care setting can be difficult for a variety of reasons. First, PTS tends to be more unfamiliar to youths and parents than other more observable disorders, such as ADHD, depression, and OCD. ${ }^{47}$ Furthermore, parents do not always have a good understanding of factors that predispose their children to developing PTS. For instance, parents may believe that their children only develop PTS after a severe trauma, while research has clearly demonstrated that subjective perceptions of threat regarding the PTE or PTE consequences are better predictors of PTS. ${ }^{48}$ Additionally, some parents may minimize or deny their children's symptoms, which may be a function of their own PTS. ${ }^{18,49}$ Moreover, avoidance symptoms may complicate the screening process as parents or youths who do not want to think about the PTE may try to ignore symptoms. ${ }^{47}$ Finally, the sheer number of potential differential or comorbid diagnoses adds complexity to the process of recognizing and accurately identifying PTS, underlying the importance of obtaining a thorough history and description of symptoms as well as assessing sociocontextual factors that may influence symptom presentation and functioning.

Should clinical report and the administration of a screening measure raise significant concerns or questions, a referral to a mental health provider can facilitate a more thorough assessment. Upon making a referral, medical providers should expect mental health providers to conduct thorough assessments including multi-informant report. Mental health providers will often include information collected and documented by school personnel (eg, teachers, administrators, guidance counselors), community members (eg, coaches, religious leaders), medical records, and police reports, when applicable.

If the child or adolescent is unable to access mental health services, medical providers may similarly consider reaching out to school personnel, community members, and obtaining medical and/or police reports to obtain more information to inform their trauma-related diagnosis. In addition, if the responsibility of conducting a more thorough assessment (ie, beyond screening) falls on the medical providers, there are a number of commonly employed and psychometrically sound measures designed to assess PTS among children and adolescents. Table 2 lists a summary of key features and considerations related to each of these tools.

\section{Supporting school-age children and adolescents with PTS}

Providers can implement preventive interventions to promote child and adolescent well-being even before experiencing a PTE. Preventive interventions can be considered a universal precaution, but may be especially helpful for youth who are at risk for trauma due to life situations, have a history of difficulty adjusting to stressful events, or are suspected of being victimized without a report of a PTE. According to Pfefferbaum et al, ${ }^{50}$ preventive interventions often include teaching coping skills, increasing affect awareness and modulation, future safety planning, and offering psychoeducation about trauma reactions. Children and adolescents who have experienced a PTE and have symptoms of PTS should receive support based on the intensity of symptoms they are experiencing, as determined by the assessment process.

\section{Children and adolescents with minimal symptomatology following a PTE}

For all children and adolescents who have experienced a PTE, a number of early intervention strategies are available to medical providers to promote recovery and resilience in the aftermath of trauma. On the basis of the results of a recent meta-analysis, the following are effective, common elements found in most early interventions: psychoeducation about typical posttraumatic reactions, promotion of coping strategies, and enhancement of social support. ${ }^{51}$ Prior to lengthy interventions or assessments for youth without impairing symptoms immediately following a PTE, Kassam-Adams et $\mathrm{al}^{42}$ recommend taking a "watchful waiting" approach. These strategies require minimal training and time and are cost less to implement, making them feasible for use within the health care system. For example, providers can offer basic education regarding PTS, encourage positive coping efforts, and monitor symptoms. Table 3 provides a list of resources available to medical providers.

\section{Children and adolescents with impairing PTS}

For children and adolescents exhibiting more severe and/or persistent PTS, referrals should be made to clinicians who are 


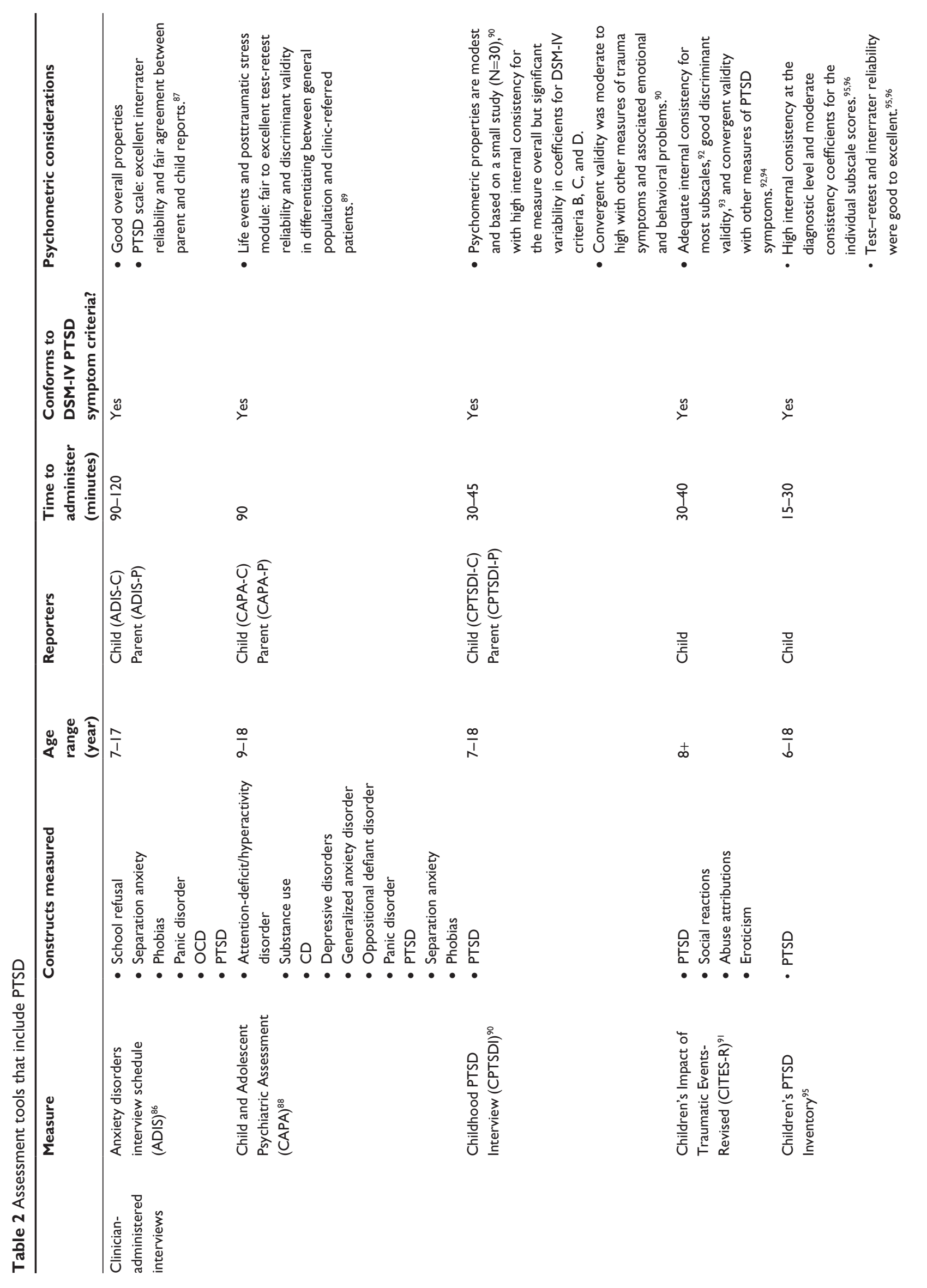



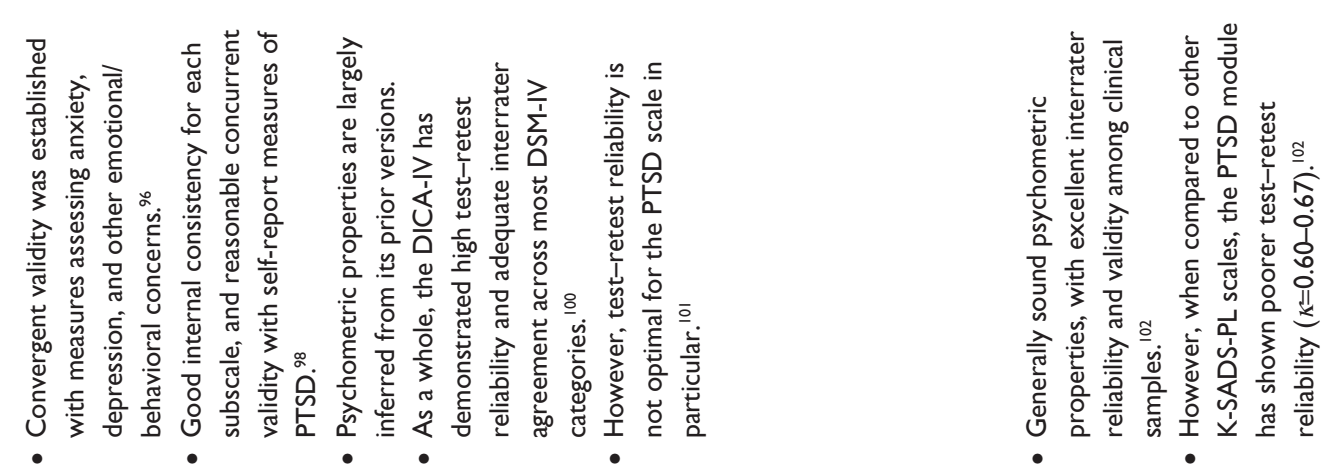

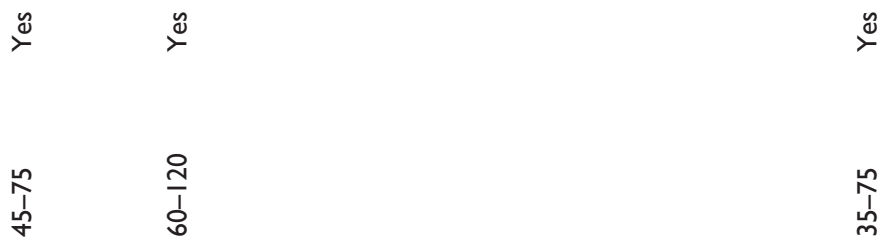

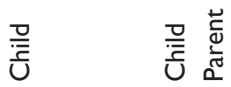

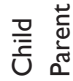

$\frac{n}{1} \quad \frac{1}{b}$

$\frac{\infty}{b}$

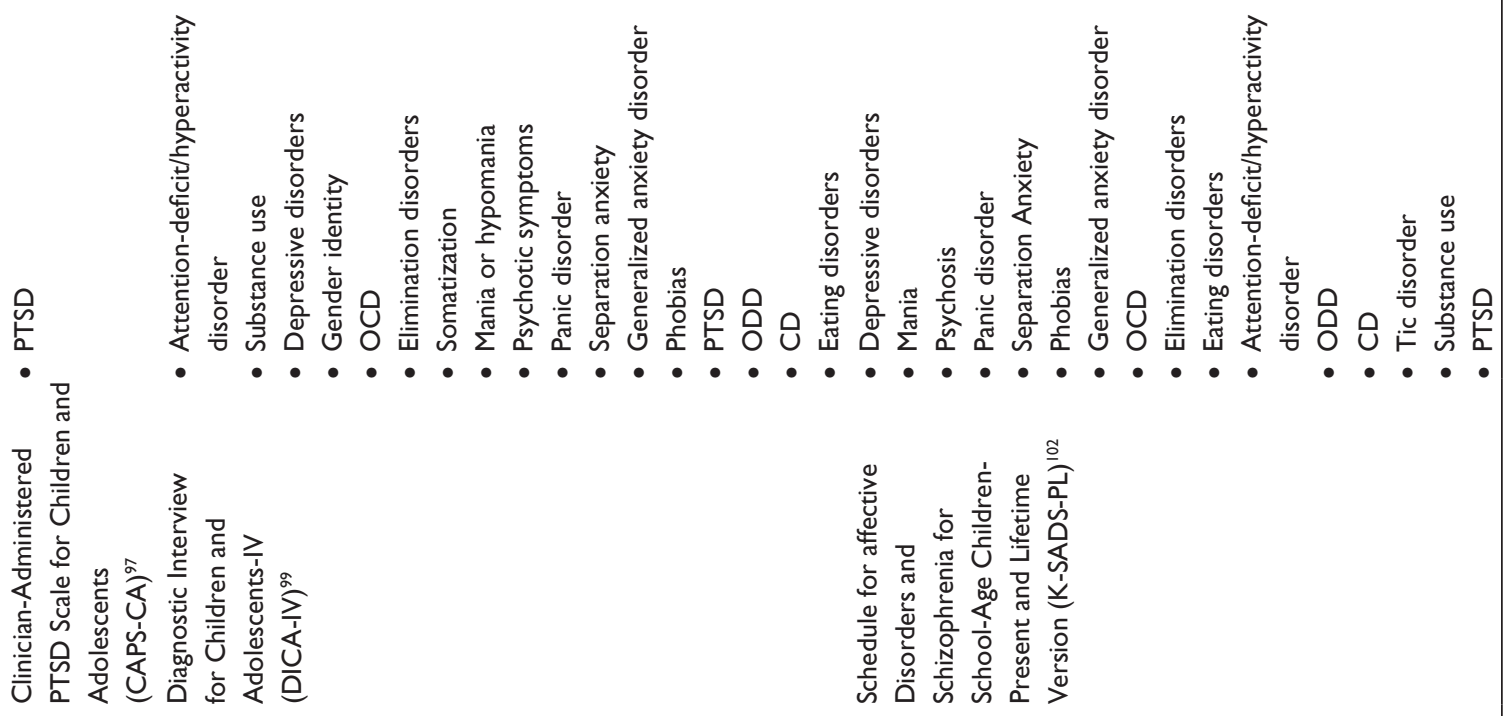




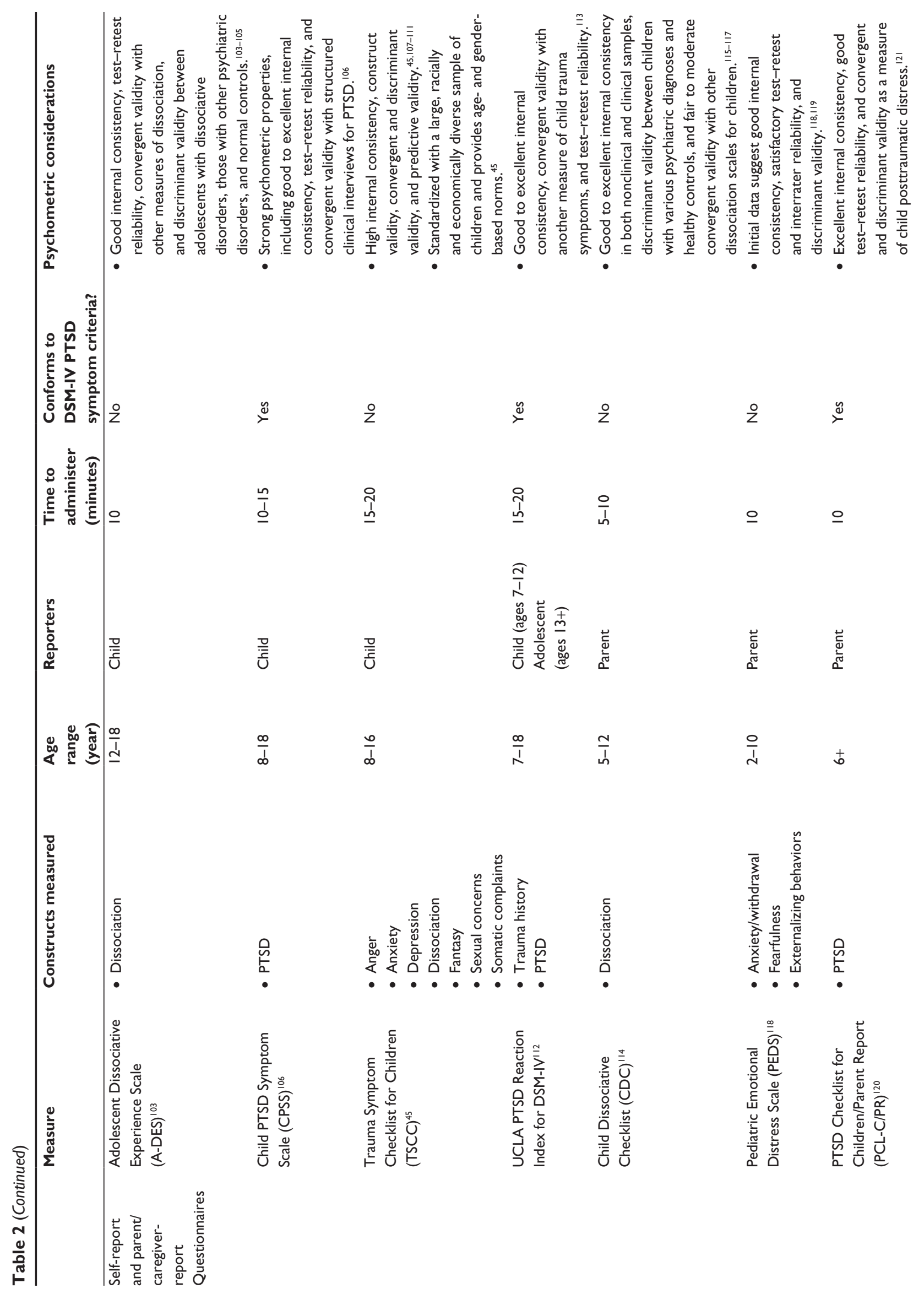


trained to treat children with PTS. Understanding the basics of these treatments can help medical providers prepare their patients for treatment and follow-up with their patients over time. Trauma-focused cognitive-behavioral therapy (TF-CBT) has the most empirical support as an efficacious treatment approach. ${ }^{52-55}$ There is also evidence to support the utility of eye movement desensitization and reprocessing therapy (EMDR) and preliminary evidence for pharmacological treatments. ${ }^{56-58}$ Other treatments including cognitive therapy, play therapy, psychological first aid, and multisystemic therapy for PTS in children are listed briefly in Table 4.

\section{Trauma-focused cognitive behavioral therapy}

TF-CBT can be particularly helpful for children and adolescents who have experienced one or more PTEs. ${ }^{53,59-62}$ It is based on the principles of cognitive behavioral therapy (CBT), which focus on examining and changing the relationships among cognitions, feelings, and behaviors. ${ }^{63-65}$ Targeting change in negative cognitions and the beliefs that influence these cognitions helps children modify their patterns of thinking and behavior to enhance coping. For example, children are encouraged to examine their unhelpful beliefs such as "I will never feel normal again", and find alternative, positive ways of thinking by generating positive self-statements and developing coping strategies. Another core aspect of treatment is exposure therapy, where children and adolescents are confronted with trauma reminders in an effort to gradually reduce avoidance of feared stimuli. ${ }^{63-65}$ The efficacy of TF-CBT has been demonstrated for youth who have experienced sexual abuse, ${ }^{53,59,61}$ natural disasters, ${ }^{66}$ accidental injury, ${ }^{60}$ and single-incident trauma, including violence. ${ }^{62} \mathrm{TF}-\mathrm{CBT}$ utilizes four primary principles of CBT to decrease PTS including psychoeducation and setting goals, coping skills, exposure and cognitive restructuring, and relapse prevention. TF-CBT differs from traditional $\mathrm{CBT}$ in that it focuses on the trauma experience and targets decreasing PTS..$^{53}$ It may be helpful for providers to keep in mind that while the exposure component of treatment is effective, it can be distressing for youth because it requires them to confront upsetting trauma reminders. Children and adolescents may need extra support from their parents and possibly medical providers during this period of time.

\section{Eye movement desensitization and reprocessing therapy}

Results from several meta-analyses suggest EMDR is comparable to other empirically supported treatments for 
Table 3 Resources for medical providers

\begin{tabular}{|c|c|c|c|c|}
\hline Resource & Target population & $\begin{array}{l}\text { Main components } \\
\text { of resource }\end{array}$ & Cost & Access \\
\hline D-E-F Protocol ${ }^{123}$ & $\begin{array}{l}\text { Health care providers of ill or } \\
\text { injured children. }\end{array}$ & $\begin{array}{l}\text { Assessment protocol for } \\
\text { trauma-informed care }\end{array}$ & No cost & https://www.healthcaretoolbox.org/ \\
\hline After the Injury ${ }^{124}$ & $\begin{array}{l}\text { Parents and health care providers } \\
\text { of injured children. }\end{array}$ & Psychoeducation & No cost & https://www.aftertheinjury.org/ \\
\hline Kids Accident Website ${ }^{125}$ & Parents of injured children. & Psychoeducation & No cost & http://kidsaccident.psy.uq.edu.au/ \\
\hline Health Care Toolbox ${ }^{126}$ & $\begin{array}{l}\text { Health care providers of ill or } \\
\text { injured children. }\end{array}$ & $\begin{array}{l}\text { Psychoeducation } \\
\text { Assessment tools }\end{array}$ & No cost & https://www.healthcaretoolbox.org/ \\
\hline $\begin{array}{l}\text { Psychological First } \\
\text { Aid Manual }{ }^{127}\end{array}$ & $\begin{array}{l}\text { Children who experienced a } \\
\text { disaster or terrorism and their } \\
\text { parents. }\end{array}$ & Training manual & No cost & $\begin{array}{l}\text { http://www.nctsn.org/content/ } \\
\text { psychological-first-aid }\end{array}$ \\
\hline $\begin{array}{l}\text { Skills for Psychological } \\
\text { Recovery }{ }^{128}\end{array}$ & $\begin{array}{l}\text { Mental health professionals and } \\
\text { disaster recovery workers aiding } \\
\text { victims in the aftermath of disaster. }\end{array}$ & Online training course & No cost & http://learn.nctsn.org/login/index.php \\
\hline $\begin{array}{l}\text { The } 12 \text { Core Concepts: } \\
\text { Concepts for Understanding } \\
\text { Traumatic Stress Responses } \\
\text { in Children and Families }{ }^{129}\end{array}$ & $\begin{array}{l}\text { Health care providers and parents } \\
\text { of children who have experienced } \\
\text { trauma. }\end{array}$ & Psychoeducation & No cost & $\begin{array}{l}\text { http://www.nctsn.org/resources/ } \\
\text { audiences/parents-caregivers/what- } \\
\text { is-cts/I2-core-concepts }\end{array}$ \\
\hline
\end{tabular}

PTS, including exposure therapy. ${ }^{56-58}$ EMDR has been effective in treatment of PTS in children and adolescents who experienced sexual abuse, ${ }^{67}$ disasters, ${ }^{68}$ interpersonal violence, ${ }^{69}$ and motor-vehicle accidents. ${ }^{70}$ The theory behind EMDR is that PTS results from insufficient processing or integration of sensory, cognitive, and affective components of the traumatic memory. During EMDR, the therapist moves his or her finger in front of the child's eyes in a lateral movement to elicit saccadic eye movements. The eye movements are thought to facilitate information processing and integration. ${ }^{71}$ Simultaneously, the child conducts imaginal exposure of the traumatic memory. The process occurs repeatedly until distress related to the traumatic memory subsides. ${ }^{72}$ However, EMDR lacks an empirically validated model for explaining the mechanism through which the eye movements are effective. It has been suggested that it is the exposure portion of the treatment that works to improve children's symptoms rather than the rapid eye movements themselves. ${ }^{73,74}$ Similar to the exposure components of TFCBT, participating in EMDR treatment can be distressing for children and adolescents at times as they are required to process trauma-related information. Medical providers can fulfill a supportive role for children and families during the treatment period by helping families know what to expect

Table 4 Treatments for PTS

\begin{tabular}{|c|c|c|}
\hline Treatment & Description of treatment & Mechanisms of change \\
\hline $\begin{array}{l}\text { Trauma focused-cognitive behavioral } \\
\text { therapy }(\mathrm{TF}-\mathrm{CBT})^{52,53,59-62,66}\end{array}$ & $\begin{array}{l}\text { Uses both cognitive and behavioral approaches to reduce PTS through } \\
\text { exposure. }\end{array}$ & $\begin{array}{l}\text { Psychoeducation } \\
\text { Coping } \\
\text { Exposure } \\
\text { Cognitive restructuring }\end{array}$ \\
\hline Cognitive therapy ${ }^{130-132}$ & Uses a cognitive approach to reduce PTS through cognitive restructuring. & $\begin{array}{l}\text { Psychoeducation } \\
\text { Coping } \\
\text { Cognitive restructuring }\end{array}$ \\
\hline $\begin{array}{l}\text { Eye movement desensitization and } \\
\text { reprocessing (EMDR) therapy }{ }^{56-58,68,69,71}\end{array}$ & Employs saccadic eye movements during imaginal exposure to trauma. & Exposure \\
\hline Play therapy ${ }^{133-135}$ & $\begin{array}{l}\text { Used for young children. Provides a safe recovery environment for children } \\
\text { to learn coping skills, and uses games and drawings to help them process } \\
\text { traumatic memories. }\end{array}$ & $\begin{array}{l}\text { Support and comfort } \\
\text { Coping }\end{array}$ \\
\hline Psychological first aid ${ }^{136,137}$ & $\begin{array}{l}\text { Used in the early aftermath of trauma. Involves providing comfort, } \\
\text { normalizing reactions, and teaching coping skills. }\end{array}$ & $\begin{array}{l}\text { Psychoeducation } \\
\text { Support and comfort } \\
\text { Coping }\end{array}$ \\
\hline Multisystemic therapy ${ }^{138,139}$ & $\begin{array}{l}\text { Designed to change nonfunctional patterns of family interactions in times } \\
\text { of stress. }\end{array}$ & $\begin{array}{l}\text { Improves family } \\
\text { interactions }\end{array}$ \\
\hline
\end{tabular}

Abbreviation: PTS, posttraumatic stress. 
and communicating any concerns to the child's mental health provider.

\section{Psychopharmacological treatments}

Research investigating psychopharmacological treatments for PTS in children and adolescents is limited. ${ }^{75}$ However, the notion that SSRIs may be an effective treatment option in combination with psychological treatment has garnered recent attention. ${ }^{76,77}$ Tareen et $\mathrm{al}^{78}$ posit that SSRIs may be beneficial for youths because of their success with adults. While evidence suggests that SSRIs, tricyclic antidepressants, $\alpha$ - and $\beta$-aderenergic blocking agents, anxiolytics, antipsychotics, and anticonvulsants successfully treat PTS in adults, ${ }^{79-83}$ these findings cannot be generalized to children and adolescents due to developmental neurobiological differences. ${ }^{84}$ Huemer et al's ${ }^{75}$ review provides a more detailed explanation of psychopharmacological treatments for youth with PTS. When prescribing medications to treat PTS in children, practitioners also need to be sure that they are up-todate on ever-changing policies of regulatory agencies. More research is needed to understand how to best support youth with psychopharmacological treatments following trauma. While nonpharmacological approaches (ie, therapy) treatment is the first line of defense for children and adolescents with significant PTS, mental health providers and medical providers may need to collaborate to explore the possibility of psychopharmacological treatment if the child or adolescent continues to experience high levels of distress and/or symptoms that interfere with functioning.

\section{Conclusion}

Medical providers play a key role in supporting school-age children and adolescents who have experienced a PTE. Exposure to PTEs place youth at risk for developing PTS, which is related to worse health and functional outcomes. ${ }^{85}$ The clinical presentation of PTS in school-age children and adolescents is complex and may include additional internalizing and externalizing symptoms or comorbid disorders. Screening and evaluation tools can help medical providers in their evaluation of which youths are at risk for significant PTS. To provide the best care for children and adolescents who have experienced trauma, providers may consider seeking additional training in delivering medical care from a trauma-informed approach. By understanding the clinical presentation of PTS, providers can help support youth at the appropriate level of care by either monitoring symptoms over time, providing basic education and supporting coping, or referring them for a more thorough evaluation and treatment by a mental health provider (Figure 1). In considering trauma exposure and symptoms in pediatric patients, medical providers can better optimize pediatric health outcomes.

\section{Disclosure}

The authors report no conflicts of interest in this work.

\section{References}

1. Finkelhor D, Ormrod, RK, Turner, HA. Lifetime assessment of polyvictimization in a national sample of children and youth. Child Abuse Negl. 2009;33:403-411.

2. McDonald R, Jouriles EN, Ramisetty-Mikler S, Caetano R, Green CE. Estimating the number of American children living in partner-violent families. J Fam Psychol. 2006;20(1):137-142.

3. Grossman D. The history of injury control and the epidemiology of child and adolescent injuries. Future Child. 2000;10(1):23-52.

4. Pronczuk J, Surdu S. Children's environmental health in the twenty first century. Ann NY Acad Sci. 2008;1140(1):143-154.

5. Kessler R, Sonnega A, Bromet E, Hughes M, Nelson C. Posttraumatic stress disorder in the National Comorbidity Survey. Arch Gen Psychiatry. 1995;52:1048-1060.

6. Kassam-Adams N, Winston FK. Predicting child PTSD: the relationship between acute stress disorder and PTSD in injured children. J Am Acad Child Adolesc Psychiatry. 2004;43(4):403-411.

7. Winston FK, Kassam-Adams N, Garcia-España F, Ittenbach R, Cnaan A. Screening for risk of persistent posttraumatic stress in injured children and their parents. JAMA. 2003;290(5):643-649.

8. La Greca AM, Lai BS, Llabre MM, Silverman WK, Vernberg EM, Prinstein MJ. Children's postdisaster trajectories of PTS symptoms: predicting chronic distress. Child Youth Care Forum. 2013;42(4):351-369.

9. Miller-Graff LE, Howell KH. Posttraumatic stress symptom trajectories among children exposed to violence. J Trauma Stress. 2015;28(1):17-24

10. Copeland WE, Keeler G, Angold A, Costello EJ. Traumatic events and posttraumatic stress in childhood. Arch Gen Psychiatry. 2007;64(5): $577-584$.

11. Zatzick DF, Jurkovich GJ, Fan M-Y, et al. Association between posttraumatic stress and depressive symptoms and functional outcomes in adolescents followed up longitudinally after injury hospitalization. Arch Pediatr Adolesc Med. 2008;162(7):642-648.

12. Furr JM, Comer JS, Edmunds JM, Kendall PC. Disasters and youth: a meta-analytic examination of posttraumatic stress. J Consult Clin Psychol. 2010;78(6):765.

13. La Greca AM, Silverman WK. Treatment and prevention of posttraumatic stress reactions in children and adolescents exposed to disasters and terrorism: what is the evidence? Child Development Perspectives. 2009;3(1):4-10.

14. La Greca AM. Understanding the psychological impact of terrorism on youth: moving beyond posttraumatic stress disorder. Clin Psychol Sci Pract. 2007;14(3):219-223.

15. Davidson JR. Recognition and treatment of posttraumatic stress disorder. J Am Med Assoc. 2001;286(5):584-588.

16. Daviss WB, Racusin R, Fleischer A, Mooney D, Ford J, McHugo G. Acute stress disorder symptomatology during hospitalization for pediatric injury $\mathrm{J}$ Am Acad Child Adolesc Psychiatry. 2000;39(5):569-575.

17. Scheeringa MS, Zeanah CH, Cohen JA. PTSD in children and adolescents: toward an empirically based algorithm. Dep and Anx. 2011;28(9):770-782.

18. deVries AP, Kassam-Adams N, Cnaan A, Sherman-Slate E, Gallagher PR, Winston FK. Looking beyond the physical injury: posttraumatic stress disorder in children and parents after pediatric traffic injury. Pediatrics. 1999;104(6):1293-1299. 
19. Ziegler MF, Greenwald MH, DeGuzman MA, Simon HK. Posttraumatic stress responses in children: awareness and practice among a sample of pediatric emergency care providers. Pediatrics. 2005;115(5): 1261-1267.

20. Zatzick DF, Kang S-M, Kim SY, et al. Patients with recognized psychiatric disorders in trauma surgery: incidence, inpatient length of stay, and cost. J Trauma Acute Care Surg. 2000;49(3):487-495.

21. Drotar D. Promoting comprehensive care for children with chronic health conditions and their families: introduction to the special issue. Child Serv Soc Pol Res Pract. 2001;4(4):157-163.

22. Kazak AE. Comprehensive care for children with cancer and their families: a social ecological framework for guiding research, practice, and policy. Child Serv Soc Pol Res Pract. 2001;4(4):217-233.

23. Zatzick DF, Jurkovich GJ, Gentilello L, Wisner D, Rivara FP. Posttraumatic stress, problem drinking, and functional outcomes after injury. Arch Surg. 2002;137(2):200-205.

24. Schappert SM, Rechsteiner EA. Ambulatory Medical Care Utilization Estimates for 2006. Hyattsville, MD: Department of Health and Human Services, Centers for Disease Control and Prevention, National Center for Health Statistics; 2008.

25. Davidson EJ, Silva TJ, Sofis LA, Ganz ML, Palfrey JS. The doctor's dilemma: challenges for the primary care physician caring for the child with special health care needs. Ambul Pediatr. 2002;2(3):218-223.

26. Leslie LK, Sarah R, Palfrey JS. Child health care in changing times. Pediatrics. 1998;101(3):746-752.

27. Cohen JA, Bukstein O, Walter H, et al. Practice parameter for the assessment and treatment of children and adolescents with posttraumatic stress disorder. J Am Acad Child Adolesc Psychiatry. 2010;49(4):414-430.

28. Carrion VG, Kletter H. Posttraumatic stress disorder: shifting toward a developmental framework. Child Adolesc Psychiatry Clin N Am. 2012;21(3):573-591.

29. Carrion VG, Weems CF, Ray R, Reiss AL. Toward an empirical definition of pediatric PTSD: The phenomenology of PTSD symptoms in youth. J Am Acad Child Adolesc Psychiatry. 2002;41(2):166-173.

30. Pynoos R, Steinberg A, Layne CM, Briggs E, Ostrowski S, Fairbank J. DSM-V PTSD diagnostic criteria for children and adolescents: a developmental perspective and recommendations. J Trauma Stress. 2009;22(5):391-398.

31. Broman-Fulks JJ, Ruggiero KJ, Green BA, Smith DW, Hanson RF, Kilpatrick DG. The latent structure of PTSD among adolescents. J Trauma Stress. 2009;22:146-152.

32. Dykman RA, McPherson B, Ackerman PT, et al. Internalizing and externalizing characteristics of sexually and/or physically abused children. Integr Physiol Behav Sci. 1997;32(1):62-83.

33. Kletter H, Weems CF, Carrion VG. Guilt and posttraumatic stress symptoms in child victims of interpersonal violence. Clin Child Psychol Psychiatry. 2009;14(1):171-183.

34. Schore A. Affect Dysregulation and Disorders of the Self. New York, NY: Norton; 2003.

35. Kessler R, Adler L, Barkley R, et al. The prevalence and correlates of adult ADHD in the United States: results from the National Comorbidity Survey Replication. Am J Psychiatry. 2006;163(4):716-723.

36. American Psychiatric Association. Diagnostic and Statistical Manual of Mental Disorders. 5th ed. Arlington, VA: American Psychiatric Publishing; 2013.

37. Glod CA, Teicher MH. Relationship between early abuse, posttraumatic stress disorder, and activity levels in prepubertal children. J Am Acad Child Adolesc Psychiatry. 1996;35(10):1384-1393.

38. Ford JD. Neurobiological and developmental research. In: Treating Complex Traumatic Stress Disorders: An Evidence-based Guide. New York, NY: Norton; 2009:31-58.

39. Ford J, Courtois CA. Defining and understanding complex trauma andcomplex traumatic stress disorders In: Courtois CA, Ford JD, editors. Treating Complex Traumatic Stress Disorders: An Evidence-based Guide. New York, NY: Norton; 2009:13-30.

40. Cloitre M, Stolbach BC, Herman JL, et al. A developmental approach to complex PTSD: childhood and adult cumulative trauma as predictors of symptom complexity. J Trauma Stress. 2009;22(5):399-408.
41. Cohen JA, Kelleher KJ, Mannarino AP. Identifying, treating, and referring traumatized children: the role of pediatric providers. Arch Pediatr Adolesc Med. 2008;162(5):447-452.

42. Kassam-Adams N, Marsac ML, Hildenbrand AK, Winston FK. Posttraumatic stress following pediatric injury: update on diagnosis, risk factors, and intervention. J Am Med Assoc. 2013;167(12):1158-1165.

43. Kassam-Adams N, Garcia-España F, Miller VA, Winston FK. Parent-child agreement regarding children's acute stress: the role of parent acute stress reactions. J Am Acad Child Adolesc Psychiatry. 2006;45(12):1485-1493.

44. Steinberg AM, Brymer MJ, Decker KB, Pynoos RS. The University of California at Los Angeles post-traumatic stress disorder reaction index. Curr Psychiatry Rep. 2004;6(2):96-100.

45. Briere J. Trauma Symptom Checklist for Children. Odessa FL: Psychological Assessment Resources; 1996.

46. Briere J, Johnson K, Bissada A, et al. The trauma symptom checklist for young children (TSCYC): reliability and association with abuse exposure in a multi-site study. Child Abuse Negl. 2001;25(8):1001-1014.

47. Cohen JA, Scheeringa MS. Posttraumatic stress disorder diagnosis in children: challenges and promises. Dialogues Clin Neurosci. 2009;11(1):91.

48. Trickey D, Siddaway AP, Meiser-Stedman R, Serpell L, Field AP. A meta-analysis of risk factors for post-traumatic stress disorder in children and adolescents. Clin Psychol Rev. 2012;32(2):122-138.

49. Winston FK, Kassam-Adams N, Vivarelli-O'Neill C, et al. Acute stress disorder symptoms in children and their parents after pediatric traffic injury. Pediatrics. 2002;109(6):e90-e90.

50. Pfefferbaum B, Varma V, Nitiema P, Newman E. Universal preventive interventions for children in the context of disasters and terrorism. Child Adolesc Psychiatric Clin N Am. 2014;23:363-382.

51. Kramer DN, Landolt MA. Characteristics and efficacy of early psychological interventions in children and adolescents after single trauma: a meta-analysis. Eur J Psychotraumatol. 2011;2.

52. Cohen JA, Mannarino AP. A treatment outcome study for sexually abused preschool children: initial findings. J Am Acad Child Adolesc Psychiatry. 1996;35:42-50.

53. Cohen JA, Deblinger E, Mannarino AP, Steer RA. A multisite randomized controlled trial for children with sexual abuse-related PTSD symptoms. J Am Acad Child Adolesc Psychiatry. 2004;43(4):393-402.

54. Kowalik J, Weller J, Venter J, Drachman D. Cognitive behavioral therapy for the treatment of pediatric posttraumatic stress disorder: a review and meta-analysis. J Behav Ther Exp Psychiatry. 2011;42(3):405-413.

55. Silverman WK, Ortiz CD, Viswesvaran C, et al. Evidence-based psychosocial treatments for children and adolescents exposed to traumatic events. J Clin Child Adolesc Psychol. 2008;37(1):156-183.

56. Bisson JI, Ehlers A, Matthews R, Pilling S, Richards D, Turner S. Psychological treatments for chronic post-traumatic stress disorder: systematic review and meta-analysis. Br J Psychiatry. 2007;190(2):97-104.

57. Bradley R, Greene J, Russ E, Dutra L, Westen D. A multidimensional meta-analysis of psychotherapy for PTSD. Am J Psychiatry. 2005;162(2):214-227.

58. Seidler GH, Wagner FE. Comparing the efficacy of EMDR and traumafocused cognitive-behavioral therapy in the treatment of PTSD: a meta-analytic study. Psychol Med. 2006;36(11):1515-1522.

59. Deblinger E, Mannarino AP, Cohen JA, Steer RA. A follow-up study of a multisite, randomized, controlled trial for children with sexual abuse-related PTSD symptoms. J Am Acad Child Adolesc Psychiatry. 2006;45(12):1474-1484.

60. Cobham VE, March S, De Young A, et al. Involving parents in indicated early intervention for childhood PTSD following accidental injury. Clin Child Fam Psychol Rev. 2012;15(4):345-363.

61. Cohen JA, Mannarino AP, Knudsen K. Treating sexually abused children: 1 year follow-up of a randomized controlled trial. Child Abuse Negl. 2005;29(2):135-145.

62. Nixon RD, Sterk J, Pearce A. A randomized trial of cognitive behavior therapy and cognitive therapy for children with posttraumatic stress disorder following single-incident trauma. J Abnorm Child Psychol. 2012;40(3):327-337. 
63. Rothbaum BO, Meadows EA, Resick PA, Foy DW. Cognitive-behavioral therapy In: Foa EB, Keane TM, Friedman MJ, editors. Effective Treatments for PTSD: Practice Guidelines from the International Society for Traumatic Stress Studies. New York, NY Guilford Press; 2000:320-325.

64. Briere J, Scott C. Principles of Trauma Therapy: A Guide to Symptoms, Evaluation, and Treatment. Thousand Oaks, CA: Sage Publications; 2012.

65. Freeman A. Clinical Applications of Cognitive Therapy. New York, NY: Springer; 2004.

66. Cohen JA, Jaycox LH, Walker DW, Mannarino AP, Langley AK, DuClos JL. Treating traumatized children after Hurricane Katrina: project Fleur-de Lis. Clin Child Fam Psychol Rev. 2009;12(1):55-64.

67. Jaberghaderi N, Greenwald R, Rubin A, Zand SO, Dolatabadi S. A comparison of CBT and EMDR for sexually-abused Iranian girls. Clin Psychol Psychother. 2004;11(5):358-368.

68. de Roos C, Greenwald R, den Hollander-Gijsman M, Noorthhoorn E, van Buuren S, de Jongh A. A randomized comparison of cognitive behavioral therapy (CBT) and eye movement desensitization and reprocessing (EMDR) in disaster-exposed children. Eur J Psychotraumatol. 2011;2.

69. Jarero I, Roque-Lopez S, Gomez J. The provision of an EMDR-based multicomponent trauma treatment with child victims of severe interpersonal trauma. J EMDR Pract Res. 2013;7(1):17-28.

70. Kemp M, Drummond P, McDermott B. A wait-list controlled pilot study of eye movement desensitization and reprocessing (EMDR) for children with posttraumatic stress disorder (PTSD) symptoms from motor vehicle accidents. Clin Child Psychol Psychiatry. 2010; 15(1):5-25.

71. Shapiro F. Eye movement desensitization and reprocessing (EMDR) and the anxiety disorders: clinical and research implications of an integrated psychotherapy treatment. J Anxiety Disord. 1999;13(1):35-67.

72. Shapiro F. Eye movement desensitization: a new treatment for posttraumatic stress disorder. J Behav Ther Exp Psychiatry. 1989;20: 211-217.

73. Gunter RW, Bodner GE. EMDR works ... but how? Recent progress in the search for treatment mechanisms. J EMDR Pract Res. 2009;3(3):161-168.

74. Perkins BR, Rouanzoin CC. A critical evaluation of current views regarding eye movement desensitization and reprocessing (EMDR): clarifying points of confusion. J Clin Psychol. 2002;58(1):77-97.

75. Huemer J, Erhart F, Steiner H. Posttraumatic stress disorder in children and adolescents: a review of psychopharmacological treatment. Child Psychiatry Hum Dev. 2010;41(6):624-640.

76. Keeshin BR, Strawn JR. Psychological and pharmacologic treatment of youth with posttraumatic stress disorder. Child Adolesc Psychiatric Clin NAm. 2014;23:399-411.

77. Cohen JA, Mannarino AP, Perel JM, Staron V. A pilot randomized controlled trial of combined trauma-focused CBT and sertraline for childhood PTSD symptoms. J Am Acad Child Adolesc Psychiatry. 2007;46(7):811-819.

78. Tareen A, Garralda ME, Hodes M. Post-traumatic stress disorder in childhood. Arch Dis Child Educ Pract Ed. 2007;92(1):1-6.

79. Alderman CP, Condon JT, Gilbert AL. An open-label study of mirtazapine as treatment for combat-related PTSD. Ann Pharmacother. 2009;43(7-8):1220-1226.

80. Bauer MS, Lee A, Li M, Bajor L, Rasmusson A, Kazis LE. Off-label use of second generation antipsychotics for posttraumatic stress disorder in the Department of Veterans Affairs: time trends and sociodemographic, comorbidity, and regional correlates. Pharmacoepidemiol Drug Saf. 2014;23(1):77-86.

81. Naylor JC, Dolber TR, Strauss JL, et al. A pilot randomized controlled trial with paroxetine for subthreshold PTSD in Operation Enduring Freedom/Operation Iraqi Freedom era veterans. Psychiatry Res. 2013;206(2):318-320.

82. Tarsitani L, De Santis V, Mistretta M, et al. Treatment with $\beta$-blockers and incidence of posttraumatic stress disorder after cardiac surgery: a prospective observational study. $J$ Cardiothorac Vasc Anesth. 2012;26(2):265-269.
83. Tucker P, Smith KL, Marx B, Jones D, Miranda R Jr, Lensgraf J. Fluvoxamine reduces physiologic reactivity to trauma scripts in posttraumatic stress disorder. J Clin Psychopharmacol. 2000;20(3): 367-372.

84. Pervanidou P. Biology of posttraumatic stress disorder in childhood and adolescence. J Neuroendocrinol. 2008;20(5):632-638.

85. Kenardy JA, Le Brocque R, Hendrikz JK, Iselin G, Anderson V, McKinlay L. Impact of posttraumatic stress disorder and injury severity on recovery in children with traumatic brain injury. $J$ Clin Child Adolesc Psychol. 2012;41(1):5-14.

86. Silverman WK, Albano A. The Anxiety Disorders Interview Schedule for Children-IV (Child and Parent Versions). San Antonio, TX: Psychological Corporation; 1996.

87. Meiser-Stedman R, Smith P, Glucksman E, Yule W, Dalgleish T. Parent and child agreement for acute stress disorder, post-traumatic stress disorder and other psychopathology in a prospective study of children and adolescents exposed to single-event trauma. $J$ Abnorm Child Psychol. 2007;35(2):191-201.

88. Angold A, Costello EJ. The child and adolescent psychiatric assessment (CAPA). J Am Acad Child Adolesc Psychiatry. 2000;39(1):39-48.

89. Costello EJ, Angold A, March J, Fairbank J. Life events and posttraumatic stress: the development of a new measure for children and adolescents. Psychol Med. 1998;28(6):1275-1288.

90. Fletcher K. Childhood PTSD interview - child form. In: Carlson EB, editor. Measurement of Stress, Trauma, and Adaptation. Lutherville, MD: Sidran Press; 1997:87-89.

91. Wolfe VV, Gentile C, Michienzi T, Sas L, Wolfe DA. The children's impact of traumatic events scake: a measure of post-sexual abuse PTSD symptoms. Behav Assessment. 1991;13:359-383.

92. Chaffin M, Shultz SK. Psychometric evaluation of the children's impact of traumatic events scale-revised. Child Abuse Negl. 2001; 25(3):401-411.

93. Wolfe VV. Measuring post-traumatic stress disorder: the children's impact of traumatic events scale-revised. APSAC Advisor. 1996;9(2):25-26.

94. Crouch JL, Smith DW, Ezell CE, Saunders BE. Measuring reactions to sexual trauma among children: comparing the children's impact of traumatic events scale and the trauma symptom checklist for children. Child Maltreat. 1999;4(3):255-263.

95. Saigh P, Yaski AE, Oberfield RA, et al. The children's PTSD inventory: development and reliability. J Trauma Stress. 2000;30:369-380.

96. YasikAE, Saigh PA, Oberfield RA, Green B, Halamandaris P, McHugh M. The validity of the children's PTSD inventory. J Trauma Stress. 2001;14(1):81-94.

97. Nader KO, Newman E, Weathers F, Kaloupek DG, Kriegler JA, Blake DD. National Center for PTSD Clinician-Administered PTSD Scale for Children and Adolescents (CAPS-CA) Interview Booklet. Los Angeles, CA: Western Psychological; 2004.

98. Newman E, McMackin R, Morrissey C, Erwin B. Addressing PTSD and trauma-related symptoms among criminally involved male adolescents. Stresspoints. 1997;11(7).

99. Reich W. Diagnostic interview for children and adolescents (DICA). J Am Acad Child Adolesc Psychiatry. 2000;39:59-66.

100. Ezpeleta L, de la Osa N, Domenech JM, Navarro JB, Losilla JM, Judez J. Diagnostic agreement between clinicians and the diagnostic interview for children and adolescents (DICA-R) in an outpatient sample. J Child Psychol Psychiatry. 1997;38:431-440.

101. Reich W, Cottler L, McCallum K, Corwin D, VanEerdewegh M. Computerized interviews as a method of assessing psychopathology in children. Compr Psychiatry. 1995;36(1):40-45.

102. Kaufman J, Birmaher B, Brent D, et al. Schedule for affective disorders and schizophrenia for school-aged children - present and lifetime version (KSADS-PL): initial reliability and validity data. $J$ Am Acad Child Adolesc Psychiatry. 1997;36:980-988.

103. Armstrong JG, Putnam FW, Carlson EB, Libero DZ, Smith SR. Development and validation of a measure of adolescent dissocation: the adolescent dissociative experiences scale. J Nerv Ment Dis. 1997;185(8):491-497. 
104. Brunner R, Parzer P, Schuld V, Resch F. Dissociative symptomatology and traumatogenic factors in adolescent psychiatry patients. J Nerv Ment Dis. 2000;188:71-77.

105. Smith SR, Carlson EB. Reliability and validity of the adolescent dissociative experiences scale. Dissociation. 1996;9(2):125-129.

106. Foa EB, Johnson K, Feeny NC, Treadwell KR. The child PTSD symptom scale: a preliminary examination of its psychometric properties. J Clin Child Psychol. 2001;30(3):376-384.

107. Elliot DM, Briere J. Forensic sexual abuse evaluations of older children: disclosures and symptomatology. Behav Sci Law. 1994; 12:261-277.

108. Evans JJ, Briere J, Boggiano AK, Barrett M. Reliability and validity of the trauma symptom checklist for children in a normal sample. Paper presented at: San Diego Conference on Responding to Child Maltreatment, San Diego, CA, 1994.

109. Lanktree CB, Gilbert AM, Briere J, et al. Multi-informant assessment of maltreated children: Convergent and discriminant validity of the TSCC and TSCYC. Child Abuse Negl. 2008;32(6):621-625.

110. Singer MI, Anglin TM, Song LY, Lunghofer L. Adolescents' exposure to violence and associated symptoms of psychological trauma. $J$ Am Med Assoc. 1995;273:477-482.

111. Wolpaw JM, Ford JD, Newman E, Davis JL, Briere J. Trauma symptom checklist for children. In: Grisso T, Vincent G, Seagrave D, editors. Handbook of Mental Health Screening and Assessment in Juvenile Justice. New York, NY: Guilford; 2005:152-165.

112. Pynoos R, Rodriguez N, Steinberg A, Stuber ML, Frederick C. The UCLA PTSD Reaction Index for DSM-IV (Revision 1). Los Angeles, CA: UCLA Trauma Psychiatry Program; 1998.

113. Steinberg AM, Brymer MJ, Kim S, et al. Psychometric properties of the UCLA PTSD reaction index: part I. J Trauma Stress. 2013;26(1):1-9.

114. Putnam FW, Helmers K, Trickett P. Development, reliability, and validity of a child dissociation scale. Child Abuse Negl. 1993;17: 731-741.

115. Ohan J, Myers K, Collett B. Ten-year review of rating scale. IV: scales assessing trauma and its effects. JAm Acad Child Adolesc Psychiatry. 2002;41(12):1401-1422.

116. Putnam FW, Peterson G. Further validation of the child dissociative checklist. Dissociation. 1994;7(4):204-211.

117. Wherry JN, Jolly JB, Feldman J, Adam B, Manjanatha S. The child dissociative checklist: preliminary findings of a screening measure. J Child Sex Abus. 1994;3(3):51-66.

118. Saylor CF, Swenson CC, Reynolds SS, Taylor M. The pediatric emotional distress scale: a brief sceening measure for young children exposed to traumatic events. J Clin Child Psychol. 1999; 28(1):70-81.

119. Spilsbury JC, Drotar D, Burant C, Flannery D, Creeden R, Friedman S. Psychometric properties of the pediatric emotional distress scale in a diverse sample of children exposed to interpersonal violence. $J$ Clin Child Adolesc Psychol. 2005;34(4):758-764.

120. Weathers F, Ford J. Psychometric review of PTSD Checklist (PCL-C, PCL-S, PCL-M, PCL-PR). In: Stamm B, editor. Measurement of Stress, Trauma, and Adaptation. Lutherville, MD: Sidran Press; 1996:250-251.

121. Daviss WB, Mooney D, Racusin R, Ford J, Fleischer A, McHugo G. Predicting posttraumatic stress after hospitalization for pediatric injury. J Am Acad Child Adolesc Psychiatry. 2000;39(5):576-583.
122. Nilsson D, Gustafsson PE, Svedin CG. The psychometric properties of the trauma symptom checklist for young children in a sample of Swedish children. Eur J Psychotraumatol. 2012;3.

123. Stuber ML, Schneider S, Kassam-Adams N, Kazak AE, Saxe G. The Medical Traumatic Stress Toolkit. CNS Spectr. 2006;11(02): 137-142.

124. Marsac ML, Kassam-Adams N, Hildenbrand AK, Kohser KL, Winston FK. After the injury: initial evaluation of a web-based intervention for parents of injured children. Health Educ Res. 2011;26(1):1-12.

125. Cox CM, Kenardy JA, Hendrikz JK. A randomized controlled trial of a web-based early intervention for children and their parents following unintentional injury. J Pediatr Psychol. 2010;35(6):581-592.

126. Kassam-Adams N, Schneider S, Kazak AE. Health Care Toolbox: Your Guide to Helping Children and Families Cope with Illness and Injury. Philadelphia, PA: Center for Pediatric Traumatic Stress; 2010.

127. The National Child Traumatic Stress Network. Psychological First Aid, Jul 2006.

128. Forbes D, Fletcher S, Wolfgang B, et al. Practitioner perceptions of skills for psychological recovery: a training programme for health practitioners in the aftermath of the Victorian bushfires. Aust $N Z J$ Psychiatry. 2010;44(12):1105-1111.

129. National Child Traumatic Stress Network Core Curriculum Task Force. 12 Core Concepts: Concepts for Understanding Traumatic Stress Responses in Children and Families, 2007.

130. Ehlers A, Mayou R, Bryant B. Cognitive predictors of posttraumatic stress disorder in children: results of a prospective longitudinal study. Behav Res Ther. 2003;41(1):1-10.

131. Meiser-Stedman R. Towards a cognitive-behavioral model of PTSD in children and adolescents. Clin Child Fam Psychol Rev. 2002;5(4):217-232.

132. Smith P, Yule W, Perrin S, Tranah T, Dalgleish T, Clark DM. Cognitive-behavioral therapy for PTSD in children and adolescents: a preliminary randomized controlled trial. $J$ Am Acad Child Adolesc Psychiatry. 2007;46(8):1051-1061.

133. Ogawa Y. Childhood trauma and play therapy intervention for traumatized children. J Prof Counsel Pract Theory Res. 2004;32(1):19.

134. Ryan V, Needham C. Non-directive play therapy with children experiencing psychic trauma. Clin Child Psycholo Psychiatry. 2001;6(3):437-453.

135. Wilson K, Ryan V. Play Therapy: A Non-directive Approach for Children and Adolescents. Edinburgh, UK: Elsevier Health Sciences; 2005.

136. Ruzek JI, Brymer MJ, Jacobs AK, Layne CM, Vernberg EM, Watson PJ. Psychological first aid. J Ment Health Counsel. 2007;29(1):17-49.

137. Vernberg EM, Steinberg AM, Jacobs AK, et al. Innovations in disaster mental health: psychological first aid. Prof Psychol Res Pract. 2008;39(4):381.

138. Henggeler SW. Efficacy studies to large-scale transport: The development and validation of multisystemic therapy programs. Ann Rev Clin Psychol. 2011;7:351-381.

139. Swenson CC, Schaeffer CM, Henggeler SW, Faldowski R, Mayhew AM. Multisystemic therapy for child abuse and neglect: a randomized effectiveness trial. J Fam Psychol. 2010;24(4):497.
Pediatric Health, Medicine and Therapeutics

\section{Publish your work in this journal}

Pediatric Health, Medicine and Therapeutics is an international, peerreviewed, open access journal publishing original research, reports, editorials, reviews and commentaries. All aspects of health maintenance, preventative measures and disease treatment interventions are addressed within the journal. Practitioners from all disciplines are invited to submit

\section{Dovepress}

their work as well as healthcare researchers and patient support groups. The manuscript management system is completely online and includes a very quick and fair peer-review system. Visit http://www.dovepress.com/ testimonials.php to read real quotes from published authors. 